\title{
Endovascular Treatment of Distal Anterior Cerebral Artery Aneurysms: Single-Center Experience and a Systematic Review
}

\author{
C.L. Sturiale, W. Brinjikji, M.H. Murad, H.J. Cloft, D.F. Kallmes, and G. Lanzino
}

\begin{abstract}
SUMMARY: In this study, a single center's experience of 20 patients and a systematic review and a meta-analysis of 16 studies, including 279 patients/aneurysms, assessed the safety and efficacy of endovascular treatment of distal anterior cerebral artery aneurysms. The authors conclude that endovascular treatment of distal anterior cerebral artery aneurysms is associated with high angiographic occlusion rates, but the complication rates are higher compared with other aneurysms in the circle of Willis.
\end{abstract}

ABBREVIATIONS: $\mathrm{DACA}=$ distal anterior cerebral artery; GOS = Glasgow Outcome Scale

$D^{i}$ istal anterior cerebral artery (DACA) aneurysms are rare, representing approximately $1-9 \%$ of all intracranial aneurysms. ${ }^{1}$ Endovascular treatment of these aneurysms presents a number of challenges. Earlier studies have reported high rates of arterial dissection, intraprocedural rupture, and incomplete occlusion rates for endovascular treatment of DACA aneurysms. ${ }^{2-5}$ Despite these initial challenges, further refinements in endovascular techniques made coil embolization emerge as a promising therapeutic option for aneurysms at this location. ${ }^{6,7}$ To clarify the safety and efficacy of endovascular treatment of DACA aneurysms, we report our experience in conjunction with a systematic review and meta-analysis of the literature.

\section{MATERIALS AND METHODS}

After institutional review board approval, we performed a retrospective analysis of all consecutive adult patients who underwent attempted endovascular treatment of intracranial aneurysms involving the DACA at a tertiary referral center (Mayo Clinic, Rochester, Minnesota) between January 1999 and September 2012. All patients provided approval for the use of their medical records for retrospective analysis. Patients were identified through a search of angiographic reports and clinical records. The following data were collected for each patient: demographic characteristics, an-

Received December 4, 2012; accepted after revision February 23, 2013

From the Departments of Neurologic Surgery (C.L.S., G.L.), and Radiology (W.B., H.J.C., D.F.K.), and Center for Science of Healthcare Delivery (M.H.M.), Mayo Clinic College of Medicine, Rochester, Minnesota.

Please address correspondence to Giuseppe Lanzino, MD, Department of Neurologic Surgery, Mayo Clinic College of Medicine, Rochester, MN 55905; e-mail: Lanzino.Giuseppe@mayo.edu

三 Indicates article with supplemental on-line tables.

http://dx.doi.org/10.3174/ajnr.A3629 giographic features, clinical presentation, and outcomes. Among the angiographic features, aneurysm size (maximum dimension as measured by $3 \mathrm{D}$ digital subtraction angiography), rupture status, location, and incidence of azygos variant were evaluated. The CT appearance of all patients with SAH was assessed by use of the Fisher scale, and the clinical status at admission for patients with subarachnoid hemorrhage was assessed by use of the Hunt and Hess Scale. Clinical outcome for all patients was assessed by use of the Glasgow Outcome Scale (GOS). Details about the endovascular procedure included use of adjuncts (balloon-assisted and stent-assisted coiling), intraprocedural complications, and degree of immediate angiographic occlusion.

\section{Outcomes and Complications}

Radiologic outcomes for endovascular coiling were stratified into 3 levels, on the basis of the degree of angiographic aneurysm filling evaluated immediately after the completion of the endovascular procedure and at last follow-up: 1) complete occlusion (100\%), defined as a lack of angiographic filling of the sac and the neck or nearly complete occlusion ( $>90 \%$ ), defined as no filling of the sac but with small residual neck filling; 2) incomplete occlusion $(<90 \%)$, defined as persistent angiographic filling of a portion(s) of the sac, and 3) failed occlusion, defined as an aneurysm that could not be embolized, without any coil introduced or left in the aneurysm. Studied periprocedural complications (within 30 days of treatment) included intraoperative rupture, parent artery occlusion, transient ischemic attack, vasospasm, and stroke.

\section{Literature Review}

A comprehensive review of the literature was performed by use of the keywords "aneurysms" "pericallosal," "distal anterior cerebral artery," "DACA," and "endovascular" to search the PubMed, 
Ovid MEDLINE, Ovid EMBASE, Scopus, and Web of Science data bases. All studies reporting patients with DACA aneurysms treated with endovascular therapy were selected. To be considered, studies had to be published in English, report more than 2 cases, and provide detailed information regarding perioperative and postoperative complications and aneurysm occlusion rates. The search strategy was developed and executed by a reference librarian and a methodologist with expertise in systematic reviews. For each study, we extracted the following information: aneurysm rupture status, immediate and delayed angiographic occlusion rates, procedural failure rates, morbidity, mortality, overall patient perioperative complication rate, iatrogenic aneurysm rupture, periprocedural stroke, vasospasm, and intraprocedural thrombosis/transient hemiparesis. In assessing overall patient perioperative complication rate, we determined the proportion of patients who had 1 or more of the following complications: iatrogenic aneurysm rupture, periprocedural stroke, vasospasm, and intraprocedural thrombosis/transient hemiparesis. For studies reporting clinical outcome according to the $\mathrm{mRS}$, the equivalent score on GOS was calculated.

\section{Statistical Analysis}

For our institutional case series, all statistical analyses were performed by use of the SAS-based statistical software package JMP 9.0 (www.jmp.com). Significant difference between continuous variables was assessed by a Student $t$ test. From each study, we assessed the cumulative incidence (event rate) and 95\% CI for each outcome. Event rates were pooled across studies by use of random-effects meta-analysis. ${ }^{8}$ Heterogeneity across studies was evaluated by use of the $I^{2}$ statistic. $^{9}$

\section{RESULTS}

\section{Institutional Series}

A total of 20 consecutive patients were included in our singlecenter series ( 18 women and 2 men). Three patients had an additional 7 aneurysms. Four of these associated aneurysms were observed and not treated because of the small size. Two patients underwent clip ligation and 1 patient underwent endovascular coil embolization for their associated aneurysms in separate sessions. Demographic, angiographic, and clinical features are summarized in On-line Table 1. The mean \pm SD age was $60.5 \pm 10.8$ (range, 38-80 years). Eleven patients (55\%) presented with SAH. In all cases, the DACA aneurysm was responsible for the SAH. Most aneurysms (19/20) were small ( $<10 \mathrm{~mm}$ in maximum diameter). The mean size of ruptured aneurysms was significantly smaller than unruptured aneurysms (4.3 versus $7.6 \mathrm{~mm}, P=$ .029). Endovascular coiling was completed successfully in every case. Immediate total/near-total angiographic obliteration was achieved in $85 \%$ of cases and was maintained at follow-up (16.6 months on average) in $69 \%(11 / 16)$ of patients. Two patients (10\%) with partial occlusion at follow-up underwent surgical clipping. No patients underwent recoiling. Two patients (10\%) had intraoperative aneurysm perforations that were controlled with additional coiling of the aneurysm. Both patients had previously ruptured aneurysms, and this procedural complication resulted in no morbidity. One patient (5\%) had intraprocedural thrombus formation that was asymptomatic and treated with in- travenous administration of abciximab (ReoPro). None of these periprocedural events resulted in permanent morbidity or mortality.

\section{Systematic Review}

Two hundred forty-one articles were retrieved after the first literature search. Among these, 53 were selected by abstract review and analyzed in detail. Fifteen studies met our inclusion/exclusion criteria and are listed in On-line Table 2. Including our own experience, a total of 16 studies were included in this meta-analysis. ${ }^{1-7,10-17}$ The total number of patients analyzed was 279 (259 from literature and 20 from our series). Fourteen studies with a total of 246 patients provided information regarding aneurysm rupture status; among them, 185 patients (75.2\%) harbored ruptured aneurysms. The largest study had 41 patients and the smallest study had 4 patients.

\section{Endovascular Technique and Short-Term Angiographic Outcomes}

The rate of total/near-total occlusion immediately after the endovascular procedure was $86 \%(95 \% \mathrm{CI}=75-92 \%)$ and the procedural failure rate was $8 \%(95 \% \mathrm{CI}=4-14 \%)$.

\section{Procedure-Related Complications}

The overall rate of operative complications was 12\% (95\% CI = $8-18 \%)$. Procedure-related ischemia and iatrogenic rupture occurred in 5\% (95\% CI $=3-9 \%)$ and 7\% (95\% CI $=4-12 \%)$ of patients, respectively. Procedure-related permanent morbidity rate was $8 \%(95 \% \mathrm{CI}=5-13 \%)$.

\section{Long-Term Angiographic and Clinical Follow-Up}

The rate of total/near-total ( $>95 \%$ ) occlusion at mean follow-up was 78\% (95\% CI $=65-88 \%)$. A good clinical recovery (including both patients with ruptured and unruptured aneurysms) was reported in $75 \%$ (95\% CI $=66-82 \%)$. The average duration of clinical follow-up was $13.47 \pm 8.73$ months (mean follow-up duration reported in $12 / 16$ of the studies). The rate of overall mortality at follow-up was 9\% (95\% CI =6-14\%) (On-line Table 3$)$.

\section{Heterogeneity and Publication Bias}

Statistical heterogeneity was low to moderate for most outcomes except for complete/near complete occlusion (immediate and at follow-up) and SAH occurrence $\left(I^{2}>50 \%\right)$. Data were limited and did not allow for additional quantitative analysis to explore causes of heterogeneity through subgroup analysis or evaluate for the presence of publication bias.

\section{DISCUSSION}

In combining outcomes data from 16 studies, this systematic review provides representative data on aneurysm occlusion rates and complications associated with endovascular treatment of DACA aneurysms. We have demonstrated high rates of total/near total occlusion for DACA aneurysms treated with endovascular embolization. However, complications are not negligible, with procedure-related morbidity rates of $8 \%$. Approximately $75 \%$ of the patients in this meta-analysis had $\mathrm{SAH}$, which probably contributes to the relatively high mortality rates (9\%) reported with endovascular treatment of DACA aneurysms. 
Ruptured DACA aneurysms cause intracerebral hemorrhage (in addition to SAH) in more than one-half of cases and are associated with worse outcome after rupture when compared with aneurysms in other locations. ${ }^{18,19}$ Complications associated with endovascular treatment of these aneurysms are not rare and probably related to a higher level of technical difficulty because of distal location, morphology (with frequent partial incorporation of the parent artery in the neck), and higher association with anatomic variations. These challenges may explain the relatively higher procedure-related complication rates compared with aneurysms in more common locations reported by some investigators. ${ }^{1-4}$ Keston et $\mathrm{al}^{2}$ demonstrated higher rates of periprocedural rupture and incomplete coiling of DACA aneurysms when compared with other circle of Willis aneurysms. In the International Study of Unruptured Intracranial Aneurysms (ISUIA), endovascular treatment of unruptured circle of Willis aneurysms was associated with a perioperative mortality rate of $2 \%$ and an overall morbidity/mortality rate of $9.3 \% .^{20}$ In a series of 600 circle of Willis aneurysms, Brisman et $\mathrm{al}^{21}$ reported an intraoperative rupture rate of $1 \%$. In a systematic review of treatment of aneurysms of the MCA, a location that has traditionally been considered a difficult location for endovascular treatment, Brinjikji et $\mathrm{al}^{22}$ demonstrated an intraoperative rupture rate of nearly $2 \%$ for unruptured aneurysms and 5\% for ruptured aneurysms. In this series, combined procedure-related morbidity and mortality were $5 \%$ and $6 \%$ for unruptured and ruptured aneurysms, respectively. In our systematic review, the overall periprocedural rupture rate was nearly $7 \%$, with a procedure related morbidity rate of $8 \%$, markedly higher than that reported for treatment of other circle of Willis aneurysms.

Early case series of coiling for ruptured pericallosal aneurysms reported low success rates and high technical difficulty. ${ }^{3,19}$ Pierot et $\mathrm{al}^{4}$ reported a coiling success rate of only $25 \%$ (2/8 patients) and concluded that endovascular therapy was at best an adjunct to surgery. ${ }^{4}$ However, with refinement of endovascular therapy, subsequent case series have reported higher technical success rates. $^{3,15,17}$ In a recently published series of 22 patients with DACA aneurysms by Cavalcanti et al, ${ }^{23}$ complete/near complete occlusion rate was $95 \%$ and 1 patient had an intraoperative rupture. In their review of the literature, recently published series reported occlusion rates of $80-100 \%$, with a procedural related morbidity rate of $9 \%$ and mortality rate of $9 \%$. Intraoperative rupture in both their series and systematic review was approximately 5\%. Our meta-analysis has similar outcomes compared with the systematic review by Cavalcanti et $\mathrm{al}^{23}$; we found aneurysmal occlusion rates of $86 \%$, iatrogenic rupture rates of $7 \%$, procedure-related morbidity rates of $8 \%$, and mortality rates of $9 \%$.

Although complication rates for endovascular treatment of DACA aneurysms remain a concern, previous studies have demonstrated that patients with ruptured pericallosal aneurysms have significantly better outcomes when treated with coiling over clipping. In a study of 86 patients ( 54 clipped and 32 coiled) harboring pericallosal aneurysms, Hui et $\mathrm{al}^{12}$ demonstrated that patients with ruptured pericallosal aneurysms fared better with endovascular therapy, with a better chance of complete recovery. Surgical and endovascular treatments of unruptured pericallosal aneurysms have similar results and outcome.
Our study has several methodologic limitations. Primarily, the available evidence is observational, nonrandomized, and noncomparative. Data in the published literature are collected retrospectively and details such as stratification of outcomes by clinical status at admission are often lacking. In addition, it is difficult to differentiate procedure-related mortality from mortality secondary to complications of SAH. Thus, it is likely that mortality secondary to treatment of pericallosal aneurysms is lower than reported in this study. The quality of evidence (confidence) is limited because of imprecision, heterogeneity, and methodologic limitations with the use of the GRADE framework (Grading of Recommendations, Assessment, Development and Evaluation). ${ }^{24-26}$ Our systematic review and case series has several strengths. We followed a comprehensive systematic review process and searched multiple data bases in an attempt to improve the precision of estimates derived from our own data. We believe that these results represent the best available evidence regarding endovascular treatment for aneurysms in an uncommon location. The outcomes reported here reflect an average incidence to be expected for this procedure across multiple settings and institutions.

\section{CONCLUSIONS}

Endovascular coiling of DACA aneurysms is associated with immediate occlusion rates of $85 \%$ and a low recurrence rate at follow-up. However, endovascular treatment of DACA aneurysms is also associated with complication rates higher than those reported for endovascular treatment of aneurysms in other locations.

Disclosures: Harry J. Cloft-UNRELATED: Grants/Grants Pending: Cordis Endovascular.* David Kallmes—UNRELATED: Consultancy: ev3,* Medtronic,* Codman*; Grants/Grants Pending: ev3,* MicroVention, ${ }^{*}$ Sequent,* Codman*; Payment for Lectures (including service on speakers bureaus): MicroVention*; Royalties: UVA Patent Foundation*; Payment for Development of Educational Presentations: ev3*; Travel/Accommodations/Meeting Expenses Unrelated to Activities Listed: MicroVention.* Giuseppe Lanzino_UNRELATED: Consultancy: Edge Therapeutics; Payment for Development of Educational Presentations: Covidien/ev3*; Travel/ Accommodations/Meeting Expenses Unrelated to Activities Listed: Boston Biomedica Associates, Comments: Investigator meeting; expenses covered by sponsor ( ${ }^{*}$ money paid to institution).

\section{REFERENCES}

1. Carvi y Nievas MN. The influence of configuration and location of ruptured distal cerebral anterior artery aneurysms on their treatment modality and results: analysis of our casuistry and literature review. Neurol Res 2010;32:73-81

2. Keston $\mathrm{P}$, White PM, Horribine L, et al. The endovascular management of pericallosal artery aneurysms. J Neuroradiol 2004;31:384-90

3. Menovsky T, van Rooij WJ, Sluzewski M, et al. Coiling of ruptured pericallosal artery aneurysms. Neurosurgery 2002;50:11-14

4. Pierot L, Boulin A, Castaings L, et al. Endovascular treatment of pericallosal artery aneurysms. Neurol Res 1996;18:49-53

5. Suzuki S, Kurata A, Yamada M, et al. Outcomes analysis of ruptured distal anterior cerebral artery aneurysms treated by endosaccular embolization and surgical clipping. Interv Neuroradiol 2011;17:49-57

6. Tournade A, Riquelme C, Musacchio M, et al. Endovascular treatment of berry intracranial aneurysms using a new detachable coil system (DCS ((R)): Detachable Coil System Cook). Interv Neuroradiol 2001;7:93-102

7. Waldenberger P, Petersen J, Chemelli A, et al. Endovascular therapy of distal anterior cerebral artery aneurysms-an effective treatment option. Surg Neurol 2008;70:368-77

AJNR Am J Neuroradiol 34:2317-20 Dec 2013 www.ajnr.org 
8. DerSimonian R, Laird N. Meta-analysis in clinical trials. Control Clin Trials 1986;7:177-88

9. Higgins JP, Thompson SG, Deeks JJ, et al. Measuring inconsistency in meta-analyses. $B M J$ 2003;327:557-60

10. Darkhabani ZM, Lazzaro MA, Zaidat OO. Pericallosal artery aneurysm treatment using Y-configuration stent-assisted coil embolization: a report of four cases. J Neurointerv Surg 2012;4:459-62

11. Huang Q, Shen J, Xu Y, et al. Endovascular treatment of ruptured distal anterior cerebral artery aneurysm. Neurol India 2010;58:259-63

12. Hui FK, Schuette AJ, Moskowitz SI, et al. Microsurgical and endovascular management of pericallosal aneurysms. J Neurointerv Surg 2011;3:319-23

13. Hussain Z, Corkill RA, Kuker W, et al. Distal aneurysms of the unpaired ACA: embryologic and therapeutic aspects. Neuroradiology 2005;47:209-14

14. Nakai Y, Sonobe M, Takigawa T, et al. Angiographical change of Guglielmi detachable coils: treated cerebral aneurysm in acute stage. Interv Neuroradiol 2004;10(Suppl 1):161-66

15. Nguyen TN, Raymond J, Roy D, et al. Endovascular treatment of pericallosal aneurysms. J Neurosurg 2007;107:973-76

16. Pandey A, Rosenwasser RH, Veznedaroglu E. Management of distal anterior cerebral artery aneurysms: a single institution retrospective analysis (1997-2005). Neurosurgery 2007;61:909-16

17. Vora N, Thomas AJ, Gupta R, et al. Endovascular treatment of distal anterior cerebral artery aneurysms: technical results and review of the literature. J Neuroimaging 2010;20:70-73
18. de Sousa AA, Dantas FL, de Cardoso GT, et al. Distal anterior cerebral artery aneurysms. Surg Neurol 1999;52:128-35

19. Lehecka $M$, Lehto $H$, Niemela $M$, et al. Distal anterior cerebral artery aneurysms: treatment and outcome analysis of 501 patients. Neurosurgery 2008;62:590-601

20. Wiebers DO, Whisnant JP, Huston J 3rd, et al. Unruptured intracranial aneurysms: natural history, clinical outcome, and risks of surgical and endovascular treatment. Lancet 2003;362:103-10

21. Brisman JL, Niimi Y, Song JK, et al. Aneurysmal rupture during coiling: low incidence and good outcomes at a single large volume center. Neurosurgery 2005;57:1103-09

22. Brinjikji W, Lanzino G, Cloft HJ, et al. Endovascular treatment of middle cerebral artery aneurysms: a systematic review and singlecenter series. Neurosurgery 2011;68:397-402

23. Cavalcanti DD, Abla AA, Martirosyan NL, et al. Endovascular management of distal ACA aneurysms: single-institution clinical experience in 22 consecutive patients and literature review. AJNR Am J Neuroradiol 2013;34:1593-99

24. Guyatt GH, Oxman AD, Kunz R, et al. GRADE guidelines 6: rating the quality of evidence-imprecision. J Clin Epidemiol 2011;64: 1283-93

25. Murad MH, Swiglo BA, Sidawy AN, et al. Methodology for clinical practice guidelines for the management of arteriovenous access. $J$ Vasc Surg 2008;48:26S-30S

26. Balshem $\mathrm{H}$, Helfand $\mathrm{M}$, Schunemann $\mathrm{HJ}$, et al. GRADE guidelines, 3: rating the quality of evidence. J Clin Epidemiol 2011; 64:401-06 